\title{
Determinants of Treatment Delays among Pulmonary Tuberculosis Patients in Enugu Metropolis, South-East, Nigeria
}

\author{
Omotowo Ishola Babatunde ${ }^{{ }^{*}}$, Eke Christopher Bismark ${ }^{2}$, Nwobi Emmanuel Amaechi ${ }^{1}$, \\ Eyisi Ifeanyi Gabriel ${ }^{1}$, Agwu-Umahi Rebecca Olanike ${ }^{1}$ \\ ${ }^{1}$ Department of Community Medicine, College of Medicine, University of Nigeria, Enugu, Nigeria \\ ${ }^{2}$ Department of Paediatrics, College of Medicine, University of Nigeria, Enugu, Nigeria \\ Email: "babatundeomotowo@yahoo.com
}

Received 29 August 2015; accepted 14 November 2015; published 17 November 2015

Copyright (C) 2015 by authors and Scientific Research Publishing Inc.

This work is licensed under the Creative Commons Attribution International License (CC BY). http://creativecommons.org/licenses/by/4.0/

(c) (i) Open Access

\begin{abstract}
Introduction: Globally, the burden of Tuberculosis is escalating. Early diagnosis and prompt initiation of treatment are essential to achieve an effective tuberculosis control programme. Objective: To investigate the duration of delay for treatment and assess the determinants of treatment delays among pulmonary tuberculosis patients in Enugu metropolis, South-East, Nigeria. Methods: This cross sectional study was conducted among 219 pulmonary tuberculosis patients in six randomly selected DOTS centres in the three LGAs in Enugu metropolis. Data were analysed using SPSS version 17, and statistical significance of association between variables was assessed using Chi-square test at $p<0.05$. STATA version 13.1 was used to calculate the positive predictors of TB treatment delays using logistic regression. Ethical clearance was obtained from the Health Research Ethics Committee of UNTH and verbal informed consent was obtained from the participants. Results: Overall, 291 respondents took part in the study, 55.7\% were males, 84.4\% were aged between 16 to 60 years, while their mean age was $35.4 \pm 12.6$ years. Most of the participants $32.9 \%, 26.9 \%$, $15.5 \%$ were traders, civil servants, and students respectively. Among the respondents, $3.6 \% \mathrm{knew}$ that Mycobacterium tuberculosis is the cause of tuberculosis. Among the participants, only 23.3\% presented for first appropriate treatment consultation within 1 - 30 days of onset of symptoms. The reasons given by the respondents for the delay are: ignorance of necessity treatment $(36.1 \%)$, Lack of money $(24.2 \%)$, no health facility close to the house $(13.2 \%)$, and other reasons $26.5 \%$.

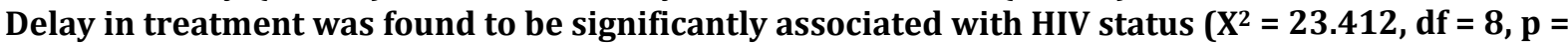
$0.003)$, knowledge of the cause of $T B\left(X^{2}=42.322, \mathrm{df}=28, \mathrm{p}=0.040\right)$, TB symptoms experienced $\left(X^{2}=46.857, \mathrm{df}=20, \mathrm{p}=0.001\right)$, occupation $\left(X^{2}=34.217, \mathrm{df}=20, \mathrm{p}=0.025\right)$, and distance of the health facility from the respondents' residence $\left(X^{2}=34.908, \mathrm{df}=8, \mathrm{p}=0.000\right)$. The positive predictors of delayed treatment, using logistic regression, were first presentation at: patent medicine ${ }^{*}$ Corresponding author.
\end{abstract}

How to cite this paper: Omotowo, I.B., Eke, C.B., Nwobi, E.A., Eyisi, I.G. and Agwu-Umahi, R.O. (2015) Determinants of Treatment Delays among Pulmonary Tuberculosis Patients in Enugu Metropolis, South-East, Nigeria. Health, 7, $1506-1516$. http://dx.doi.org/10.4236/health.2015.711164 
dealer (OR 12.3 CI: 3.22 - 36.23), private hospital (OR 10.6 CI: 5.73 - 17.94), prayer house (OR 7.2 CI: 2.75 - 23.64), and traditional healer (OR 11.9 CI: 6.87 - 32.85). Conclusion: Majority of TB patients in this study did not present early to health facilities. The positive predictors of delayed presentation for appropriate PTB treatment were first presentations at inappropriate treatment centres. There is need to intensify public health awareness among potential TB patients on the associated risks of treatment delay to prevent transmission. Unskilled health care providers should refer suspected PTB patients promptly to facilitate their treatment.

\section{Keywords}

\section{Determinants, Delay, Tuberculosis}

\section{Introduction}

Approximately one third of the world's population are infected with tuberculosis bacilli and at risk of developing active tuberculosis (TB) [1]. In 2012, there were an estimated 13 million TB cases, including 8.6 million incident cases and 1.3 million died from the disease [1]. Smear-positive pulmonary TB, the most likely source of TB transmission in the community constitutes $35 \%$ of new TB cases.

Most tuberculosis patients were not visiting health facility but transmit disease to healthy individuals in the community for longer time in Nigeria [2] [3]. Nigeria is ranked $13^{\text {th }}$ among the 22 high burden countries for TB in the world and $3^{\text {rd }}$ in Africa [1] [2]. The 2012 national TB prevalence survey in Nigeria revealed that $75 \%$ of the previously undetected cases had sputum smear positive [1] [2].

Early diagnosis of the disease and prompt initiation of treatment are essential for an effective tuberculosis control programme. Delay in the diagnosis may worsen the disease, increase the risk of death and enhance tuberculosis transmission in the community [4]. Also, it is estimated that an untreated smear-positive patient can infect between ten and fifteen contacts annually, and over 20 during the natural history of the disease until death [2] [5]-[7]. The importance of having effective methods of early detection and prompt treatment of the cases in the communities cannot be ignored [7].

Studies conducted in several countries have shown that patient and health care delay are major problems in the control of tuberculosis. The study conducted at the North Middlesex University, London, UK reported median patient related delay between 34.5 and 54 days, median health related delay was 29.5 days [8]. Considerable delays were observed in the studies done in Japan [9] [10]. Median patient delay of 60 days was documented in a study conducted in Tanzania [11].

Studies conducted in Ibadan and Lagos in South-West, Nigeria revealed high prevalence of treatment delay among pulmonary TB patients [3] [12]. These delays are attributable to patients and doctors. Another study from Nigeria showed that the mean patient delay was $13.2 \pm 7.4$ weeks [13]. Causes of these delays should be investigated to be able to control TB effectively. Our study was aimed at estimating duration of delay for treatment by pulmonary TB patients in Enugu metropolis and assessing the determinants of patient related factors associated with the treatment delays.

\section{Methods}

\subsection{Background}

The study was conducted among pulmonary tuberculosis patients in Enugu metropolis. Enugu is the capital of old Eastern region, and current Enugu state in south-east, Nigeria, with estimated population of 722,664 people. The metropolis has three Local Government Areas which are Enugu east, Enugu south and Enugu north. There are sixteen DOTS centres in Enugu metropolis. In Enugu state, tuberculosis is treated free. Diagnosis and treatment of TB patients are according to the National Tuberculosis Control Programme guidelines. All the DOTS centres treat both sputum smear positive and sputum smear negative pulmonary TB cases. All presumptive TB cases (TB suspects) submit two sputum samples by using spot-early morning approach for sputum smear microscopy, and also do HIV counselling. A sputum smear positive TB case is when one or two samples are positive [2]. The laboratory diagnosis of TB rests mainly on the identification of the tubercle bacilli in a clinical 
specimen by using any of the following laboratory methods available; microscopy, culture or new molecular tests e.g. Gene Xpert MTB/RIF and line probe assays [2]. Smear negative cases are diagnosed on clinical findings, and chest $\mathrm{x}$ ray. All new pulmonary TB patients who were diagnosed were recruited into our study.

\subsection{Study Design}

A cross sectional study was conducted among all new pulmonary tuberculosis patients who were diagnosed and commenced treatment during February 1 to October 30, 2014 in six randomly selected among the sixteen DOTS centres in the three local government areas in Enugu metropolis. All patients that participated in the study are new as part of the inclusion criteria, while all extra-pulmonary tuberculosis patients were excluded. All the subjects were interviewed using structured questionnaire. The questions were pretested and the interviewers were supervised regularly throughout the duration of the study. All the questions were closed and included sociodemographic characteristics, knowledge of pulmonary tuberculosis which includes tuberculosis symptoms, transmission and treatment. Also, they were asked duration of symptoms before first visit to the health facility, places they sought for treatment before first visit to the health facility, reasons for delay before visit to the health facility and distance from their residence to the health facility.

\subsection{Definitions of Different Types of Delays}

Patient delay is when the time interval from the appearance of the major pulmonary TB symptoms until the first visit to a medical facility exceeds 30 days. Health facility referral delay is when the time interval between the first visit to a health facility and the time the patient is seen at any health facility with DOTS services exceed two days. Diagnosis delay is when the time between first consultation at a health facility with DOTS services and a time when a definitive diagnosis of tuberculosis is made exceeded three days. Treatment delay is when interval between the time of diagnosis and treatment initiation exceeded one day. Health facility delay is when the time interval from when the patients were first seen at health facility with DOTS and treatment initiation exceeded five days. Total delay is the sum of patient delay and health service delay [11] [14].

\subsection{Ethical Approval}

Ethical approval was obtained from Health Research Ethics Committee of University of Nigeria Teaching Hospital (UNTH), Enugu. Permission was obtained from National TB Control Programme, Enugu State, Heads of all the health centres, and DOTS providers in the facilities used for the study.

Verbal informed consent was obtained from all study participants after explaining benefits of the study and assurance of confidentiality.

\subsection{Data Analysis}

Data collected from 219 pulmonary TB patients was analysed using SPSS version17 and statistical significance of association between variables was assessed using Chi-square test at $\mathrm{p}<0.05$. The positive predictors of delayed treatment were calculated by STATA version 13.1. Also, the Odds Ratio and Confidence Interval were calculated to identify the factors associated with the delay in seeking treatment using bivariate and multivariate logistic regression analysis. Variables that were significant at a level of up $10 \%$ on bivariate analysis were included in multivariate logistic regression.

\section{Results}

\subsection{Socio-Demographic Characteristics of the Study Participants}

A total of 219 newly diagnosed pulmonary tuberculosis patients (PTB) were enrolled in the 10 months study period, of which 122 (55.7\%) were males and 97 (44.3\%) were females. The mean age was $35.4 \pm 12.6$ years. Among the study participants, One hundred and fifty nine (72.6\%) had sputum smear positive, while 60 (27.3\%) were HIV positive. Most of the participants: 72 (32.9\%), 59 (26.9\%), 34 (15.5\%) were traders, civil servants, and students respectively, while 15 (6.8\%) were unemployed. With regards to education 15 (6.8\%) had no formal education, 33 (15.1\%) completed primary education, while 83 (37.9\%) and 88 (40.2\%) had secondary and tertiary education respectively. Majority of the participants 177 (80.8\%) are Igbos, while Yorubas and Hausas were 19 (8.7\%) and 11 (5\%) respectively. Also, majority of the participants 94 (42.9\%) had income of less than 
N40,000 (\$200) per annum, while only $3(1.4 \%)$ had income $>1,000,000$ naira $(>\$ 5000)$ per annum. The most prominent religion among the participants is Christianity $183(83.6 \%)$, while $20(9.1 \%)$ and $15(6.8 \%)$ were Muslims and African traditional worshipers respectively. One hundred and three participants (47\%) had more than 5 individuals per household, while 30 (13.7\%) and 86 (39.3\%) had between 1 - 2 and 3 - 5 individuals per household (Table 1).

Table 1. Socio-demographic characteristics of the participants and duration of delay.

\begin{tabular}{|c|c|c|c|c|c|c|c|}
\hline \multirow{2}{*}{ VARIBLES } & \multirow{2}{*}{ CATEGORY } & \multicolumn{2}{|c|}{ DELAYED DURATION (>30 Days) } & \multicolumn{2}{|c|}{ DURATION ( $\leq 30$ Days) } & \multicolumn{2}{|c|}{ TOTAL } \\
\hline & & $\mathbf{N}$ & $\%$ & $\mathbf{N}$ & $\%$ & $\mathbf{N}$ & $\%$ \\
\hline \multirow{2}{*}{ Sex } & Male & 92 & 75.4 & 30 & 24.6 & 122 & 55.7 \\
\hline & Female & 61 & 62.9 & 36 & 37.1 & 97 & 44.3 \\
\hline \multirow{5}{*}{ Age grp (Years) } & $0-15$ & 5 & 71.5 & 2 & 28.5 & 7 & 3.2 \\
\hline & $>15-30$ & 46 & 68.6 & 21 & 31.4 & 67 & 30.6 \\
\hline & $>30-45$ & 76 & 92.7 & 6 & 7.3 & 82 & 37.4 \\
\hline & $>45-60$ & 24 & 66.7 & 12 & 33.3 & 36 & 16.4 \\
\hline & $>60$ & 20 & 74.1 & 7 & 25.9 & 27 & 12.3 \\
\hline \multirow{5}{*}{ Marital Status } & Single & 65 & 90.3 & 7 & 9.7 & 72 & 32.9 \\
\hline & Married & 98 & 77.8 & 28 & 22.2 & 126 & 57.5 \\
\hline & Divorced & 3 & 60.0 & 2 & 40.0 & 5 & 2.3 \\
\hline & Widowed & 11 & 73.3 & 4 & 26.7 & 15 & 6.8 \\
\hline & Not Documented & 1 & 100 & 0 & 0 & 1 & 0.5 \\
\hline \multirow{6}{*}{ Occupation } & Student & 21 & 61.8 & 13 & 38.2 & 34 & 15.5 \\
\hline & Civil Servant & 31 & 52.6 & 28 & 47.3 & 59 & 26.9 \\
\hline & Trader & 57 & 79.2 & 15 & 20.8 & 72 & 32.9 \\
\hline & House wife & 3 & 42.8 & 4 & 57.2 & 7 & 3.2 \\
\hline & Unemployed & 9 & 60.0 & 6 & 40.0 & 15 & 6.8 \\
\hline & Others & 21 & 65.6 & 11 & 34.4 & 32 & 14.7 \\
\hline \multirow{4}{*}{ Education Level } & No formal education & 13 & 86.7 & 2 & 13.3 & 15 & 6.8 \\
\hline & Primary & 28 & 84.8 & 5 & 15.2 & 33 & 15.1 \\
\hline & Secondary & 59 & 71.1 & 24 & 28.9 & 83 & 37.9 \\
\hline & Tertiary & 68 & 77.3 & 20 & 22.7 & 88 & 40.2 \\
\hline \multirow{4}{*}{ Tribe } & Igbo & 143 & 80.8 & 34 & 19.2 & 177 & 80.8 \\
\hline & Yoruba & 8 & 42.1 & 11 & 57.9 & 19 & 8.7 \\
\hline & Hausa & 8 & 72.7 & 3 & 27.3 & 11 & 5.0 \\
\hline & Others & 7 & 58.3 & 5 & 41.7 & 12 & 5.4 \\
\hline \multirow{4}{*}{ Religion } & Christianity & 98 & 53.6 & 85 & 46.4 & 183 & 83.6 \\
\hline & Islam & 12 & 60.0 & 8 & 40.0 & 20 & 9.1 \\
\hline & African traditional religion & 7 & 46.7 & 8 & 53.3 & 15 & 6.8 \\
\hline & Others & 1 & 100 & 0 & 0 & 1 & 0.5 \\
\hline \multirow{4}{*}{ Annual income } & $<\mathrm{N} 40,000$ & 46 & 48.9 & 48 & 51.1 & 94 & 42.9 \\
\hline & $>\mathrm{N} 40,000-80,000$ & 28 & 62.2 & 17 & 37.8 & 45 & 20.5 \\
\hline & $>\mathrm{N} 80,000-1000,000$ & 39 & 50.6 & 38 & 49.4 & 77 & 35.2 \\
\hline & $>\mathrm{N} 1000,000$ & 2 & 66.7 & 1 & 33.3 & 3 & 1.4 \\
\hline \multirow{3}{*}{$\begin{array}{l}\text { No of individual } \\
\text { per household }\end{array}$} & 1 - 2 & 17 & 56.7 & 13 & 43.3 & 30 & 13.7 \\
\hline & $3-5$ & 37 & 43.0 & 49 & 57.0 & 86 & 39.3 \\
\hline & $>5$ & 74 & 71.8 & 29 & 28.2 & 103 & 47.0 \\
\hline
\end{tabular}




\subsection{Knowledge and Symptoms Experienced by the Study Participants.}

Table 2 shows that majority of the participants 30.6\%, 21.9\% and $21.9 \%$ believed that alcohol, smoking and dust are the causes of TB respectively, while only $0.9 \%$ knew that mycobacterium tuberculosis is the cause. Also, most of the participants (93.1\%) knew that cough is a symptom. Among the participants, $83.1 \%, 11.8 \%$ and $0.9 \%$ knew that TB can be transmitted through cough, sneezing and talking respectively, while $4.2 \%$ believed sharing of spoons or cups could transmit it. Majority of the participants (94.9\%) experienced cough, but $0.9 \%, 0.55$ and $1.9 \%$ experienced haemoptysis, weight loss and night fever respectively.

\subsection{Facilities First Attended and Delay by TB Patients}

The facilities patients first visited included patent medicine dealer: 75 (34.2\%), hospital: 83 (37.9\%), prayer house: 14 (6.4\%), traditional healers: 19 (8.7\%), while those that visited other places were 28 (12.8\%) (Table 3).

Among the study participants, 168 (76.7\%) delayed presentation to the DOTS facilities. The study also

Table 2. Knowledge and symptoms experienced by the study participants.

\begin{tabular}{|c|c|c|c|c|c|c|c|}
\hline \multirow{2}{*}{ VARIBLES } & \multirow{2}{*}{ CATEGORY } & \multicolumn{2}{|c|}{ DELAYED DURATION (>30 Days) } & \multicolumn{2}{|c|}{ DURATION ( $\leq 30$ Days) } & \multicolumn{2}{|c|}{ TOTAL } \\
\hline & & $\mathbf{N}$ & $\%$ & $\mathbf{N}$ & $\%$ & $\mathbf{N}$ & $\%$ \\
\hline \multirow{6}{*}{ Causes of TB } & Alcohol & 40 & 59.7 & 27 & 40.3 & 67 & 30.6 \\
\hline & Smoking & 29 & 60.4 & 19 & 39.6 & 48 & 21.9 \\
\hline & Mycobacterium ТВ & 0 & 0 & 2 & 100 & 2 & 0.9 \\
\hline & Dust & 18 & 37.5 & 30 & 62.5 & 48 & 21.9 \\
\hline & Witchcraft & 5 & 33.3 & 10 & 66.7 & 15 & 6.9 \\
\hline & Others & 24 & 61.5 & 15 & 38.5 & 39 & 17.8 \\
\hline \multirow{5}{*}{ Symptoms of TB } & Cough & 106 & 51.9 & 98 & 48.1 & 204 & 93.1 \\
\hline & Cough up of blood & 4 & 66.7 & 2 & 33.3 & 6 & 2.8 \\
\hline & Weight loss & 1 & 33.3 & 2 & 66.7 & 3 & 1.4 \\
\hline & Fever at night & 1 & 25.0 & 3 & 75.0 & 4 & 1.8 \\
\hline & Difficulty in breathing & 1 & 50.0 & 1 & 50.0 & 2 & 0.9 \\
\hline \multirow{3}{*}{ Spread of $\mathbf{T b}$} & Coughing & 72 & 45.1 & 110 & 54.9 & 182 & 83.1 \\
\hline & Sneezing & 12 & 46.2 & 14 & 53.8 & 26 & 11.8 \\
\hline & Speaking & 0 & 0 & 2 & 100 & 2 & 0.9 \\
\hline \multirow{4}{*}{$\begin{array}{c}\text { TB is always associated } \\
\text { with HIV }\end{array}$} & Sharing spoons or cups & 6 & 66.7 & 3 & 33.3 & 9 & 4.2 \\
\hline & No & 50 & 65.8 & 26 & 34.2 & 76 & 34.7 \\
\hline & Yes & 29 & 30.5 & 66 & 69.5 & 95 & 43.4 \\
\hline & Don’t Know & 26 & 54.2 & 22 & 45.8 & 48 & 21.9 \\
\hline \multirow{6}{*}{ Symptoms experienced } & Cough & 76 & 36.5 & 132 & 63.5 & 208 & 94.9 \\
\hline & Coughing up blood & 1 & 50.0 & 1 & 50.0 & 2 & 0.9 \\
\hline & Weight loss & 1 & 100 & 0 & 0 & 1 & 0.5 \\
\hline & Fever at night & 1 & 25 & 3 & 75 & 4 & 1.9 \\
\hline & Fatigue & 1 & 50 & 1 & 50 & 2 & 0.9 \\
\hline & Chest pain & 0 & 0 & 2 & 100 & 2 & 0.9 \\
\hline
\end{tabular}

Table 3. Facilities TB patients go first.

\begin{tabular}{|c|c|c|c|c|c|c|c|}
\hline \multirow{2}{*}{ VARIBLES } & \multirow{2}{*}{ CATEGORY } & \multicolumn{2}{|c|}{ DELAYED DURATION (>30 Days) } & \multicolumn{2}{|c|}{ DURATION ( $\leq 30$ Days) } & \multicolumn{2}{|c|}{ TOTAL } \\
\hline & & $\mathbf{N}$ & $\%$ & $\mathbf{N}$ & $\%$ & $\mathbf{N}$ & $\%$ \\
\hline \multirow{5}{*}{ Facilities they go first } & Patent medicine dealer & 52 & 69.3 & 23 & 30.7 & 75 & 34.2 \\
\hline & Hospital & 49 & 59.0 & 34 & 41 & 83 & 37.9 \\
\hline & Prayer house & 6 & 42.9 & 8 & 57.1 & 14 & 6.4 \\
\hline & Traditional healers & 10 & 52.6 & 9 & 47.4 & 19 & 8.7 \\
\hline & Others & 15 & 53.6 & 13 & 46.4 & 28 & 12.8 \\
\hline
\end{tabular}


revealed that 75 (34.3\%), 32 (14.6\%), and 24 (10.9\%) delayed treatment for 6 weeks, 8 weeks, and 12 weeks respectively; while 37 (16.9\%) delayed for more than 16 weeks.

Reasons given by the respondents for delay included lack of money 53 (24.2\%), long distance of health facility from residence 79 (36.1\%), Thirty eight (17.3\%) felt it was not necessary to seek treatment. Lack of awareness of DOTS 24 (10.9\%), while those that gave other reasons were 25 (11.5\%) (Table 4).

Patient's delay was found to be significantly associated with HIV status $\left(X^{2}=23.412, P=0.003\right)$, distance of DOTS facility from the patient's residence $\left(X^{2}=34.908, P=0.000\right)$, symptoms experienced by TB patients $\left(X^{2}\right.$ $=46.857, \mathrm{P}=0.001)$, knowledge about the causes of TB $\left(\mathrm{X}^{2}=42.322, \mathrm{P}=0.040\right)$ and occupation of the participants $\left(\mathrm{X}^{2}=34.217, \mathrm{P}=0.025\right)$. However, the study revealed that patients' delays were not significantly associated with age $\left(X^{2}=24.057, P=0.088\right)$, level of educational $\left(X^{2}=20.194, P=0.064\right)$ and sex of the patients $\left(X^{2}\right.$ $=1.310, \mathrm{P}=0.861$ ) (Table 5).

\subsection{Predictors of TB Treatment Delay}

The positive predictors of delayed treatment, using logistic regression, were first presentation at: patent medicine dealer (OR 12.3 CI: 3.22 - 36.23), private hospital (OR 10.6 CI: 5.73 - 17.94), prayer house (OR 7.2 CI: 2.75 - 23.64), and traditional healer (OR 11.9 CI: 6.87 - 32.85), distance of DOTS facility from the residence (OR 3.6, CI: 1.41 - 16.35), HIV (OR 2.4 CI: 1.0 - 15.5), Occupation (OR 5.3 CI: 1.1 - 14.3) and symptoms experienced (OR 7.6 CI: 2.9 - 20.8) (Table 6).

\subsection{Delay of Seeking Treatment by TB Patients}

Among the study participants, 168 (76.7\%) of patients delayed seeking treatment at the DOTS facility. The mean delay from onset of symptoms to first visit to the DOTS facility was $10.2 \pm 7.3$ weeks. The maximum patient delays was found in 37 (16.9\%) patients who first presented at DOTS facility after 12 weeks, while 131 (59.8\%) presented between 4 - 12 weeks after the onset of symptoms (Table 7).

\section{Discussion}

Understanding the factors associated with patient delays is vital for the achievement of the Global Plan to Stop TB, which aims to halve the prevalence and deaths from TB by 2015 [15]. It is also known that early detection and treatment of TB patients are one of the strategies of WHO to reduce the diseases morbidity and mortality throughout the world. Our study estimated the duration of delay in seeking treatment at DOTS facilities, and factors associated with the delay. The overall median delay among TB patients in our study was 10 weeks. The median delay in this study is longer than in the studies conducted by Fatiregun and Ejeckam in Nigeria, Odusanya and Babafemi in Nigeria, Endalew et al. in Ethiopia, Tegegn et al. in Ethiopia, and Alexis et al. in Cameroon where 60 days, 60 days, 30 days, 63 days, and 30 days were found respectively [3] [11] [16]-[18]. However, the delay is shorter than in the study done in Tanzania [19] where 120 days was found, but similar to a study done in Ethiopia [11] where duration of 78 days was reported. The long delay might be due to the fact that the symptoms mostly experienced by TB patients are thought to be mild that could be treated by traditional healers and other non medical facilities. Some symptoms experienced may be taken for mild chest infections which they just take self medication or visit patent medicine dealers. More than $60 \%$ of the patients first went to patent medicine dealers, prayer houses, and traditional healers for treatment after the onset of the symptoms. Most of the patients (69.3\%) that went for treatment at patent medicine dealers delayed seeking treatment at DOTS facility. This could be as a result of poor collaboration between the National TB control programme and patent medicine dealers in the study area. There is need to improve public private partnership with National TB control programme so that TB suspects will be referred early to DOTS facilities for sputum smear microscopy and other investigations necessary for confirmation of tuberculosis. However, the proportion of patients (76.7\%) who delayed presentation at the DOTS facility in this study are similar to studies conducted in Tanzania, and Ethiopia [11] [19], but slightly less than 83\%, and 81\% found in the studies done in Lagos, Nigeria [12] [20].

In our study, the major reasons for delay are far distance of the DOTS facility (36.1\%) and poor socio-economic conditions (24.2\%). Other reasons that contributed to the delay include lack of awareness of DOTS, and some felt it was not necessary. These reasons were similar to those reported in the study in Syrian Arab Republic conducted among 800 new smear positive pulmonary TB patients, and in Zambia where lack of 
Table 4. Reasons for delay for more than 30 days before presentation at DOTS facility.

\begin{tabular}{lll}
\hline Reasons: & N & \% \\
\hline Poor socio-economic condition & 53 & 24.2 \\
Distance of health facility far & 79 & 36.1 \\
Felt not necessary & 38 & 17.3 \\
Lack of awareness of DOTS & 24 & 10.9 \\
Others & 25 & 11.5 \\
\hline
\end{tabular}

Table 5. Relationship of different variables with treatment delay.

\begin{tabular}{|c|c|c|c|c|c|c|c|c|c|}
\hline \multirow{2}{*}{ VARIBLES } & \multirow{2}{*}{ CATEGORY } & \multicolumn{2}{|c|}{$\begin{array}{c}\text { DELAYED DURATION } \\
\text { (>30 Days) }\end{array}$} & \multicolumn{2}{|c|}{$\begin{array}{c}\text { DURATION } \\
\text { ( } \leq 30 \text { Days) }\end{array}$} & \multicolumn{2}{|c|}{ TOTAL } & \multirow{2}{*}{$\begin{array}{c}\text { Chi-square } \\
\qquad \mathrm{X}^{2}\end{array}$} & \multirow{2}{*}{$\begin{array}{c}\text { P-Value } \\
\text { P }\end{array}$} \\
\hline & & $\mathbf{N}$ & $\%$ & $\mathbf{N}$ & $\%$ & $\mathbf{N}$ & $\%$ & & \\
\hline \multirow{3}{*}{ HIV status } & Positive & 65 & 76.5 & 20 & 23.5 & 85 & 38.8 & \multirow{3}{*}{23.412} & \multirow{3}{*}{0.003} \\
\hline & Negative & 68 & 73.1 & 25 & 26.9 & 93 & 42.5 & & \\
\hline & Unknown & 35 & 85.4 & 6 & 14.6 & 41 & 18.7 & & \\
\hline \multirow{4}{*}{$\begin{array}{c}\text { Level of } \\
\text { Education }\end{array}$} & No formal education & 13 & 86.7 & 2 & 13.3 & 15 & 6.8 & \multirow{4}{*}{20.194} & \multirow{4}{*}{0.064} \\
\hline & Primary & 28 & 84.8 & 5 & 15.2 & 33 & 15.1 & & \\
\hline & Secondary & 59 & 71.1 & 24 & 28.9 & 83 & 37.9 & & \\
\hline & Tertiary & 68 & 77.3 & 20 & 22.7 & 88 & 40.2 & & \\
\hline \multirow{3}{*}{$\begin{array}{c}\text { Distance of } \\
\text { DOTS Center }\end{array}$} & $<5 \mathrm{~km}$ & 51 & 61.4 & 32 & 38.6 & 83 & 37.9 & \multirow{3}{*}{34.908} & \multirow{3}{*}{0.000} \\
\hline & $5-10 \mathrm{~km}$ & 83 & 83.8 & 16 & 16.2 & 99 & 45.2 & & \\
\hline & $>10 \mathrm{~km}$ & 34 & 91.9 & 3 & 8.1 & 37 & 16.9 & & \\
\hline \multirow{5}{*}{$\begin{array}{c}\text { Symtoms } \\
\text { experienced }\end{array}$} & Cough & 106 & 51.9 & 98 & 48.1 & 204 & 93.1 & \multirow{5}{*}{46.857} & \multirow{5}{*}{0.001} \\
\hline & Haemoptysis & 4 & 66.7 & 2 & 33.3 & 6 & 2.8 & & \\
\hline & Weight loss & 1 & 33.3 & 2 & 66.7 & 3 & 1.4 & & \\
\hline & Night fever & 1 & 25.0 & 3 & 75.0 & 4 & 1.8 & & \\
\hline & Breathing difficulty & 1 & 50.0 & 1 & 50.0 & 2 & 0.9 & & \\
\hline \multirow{6}{*}{$\begin{array}{l}\text { Knowledge } \\
\text { about causes } \\
\text { of TB }\end{array}$} & Alcohol & 40 & 59.7 & 27 & 40.3 & 67 & 30.6 & \multirow{6}{*}{42.322} & \multirow{6}{*}{0.040} \\
\hline & Mycobacterium Tuberculosis & 0 & 0 & 2 & 100 & 2 & 0.9 & & \\
\hline & Smoking & 29 & 60.4 & 19 & 39.6 & 48 & 21.9 & & \\
\hline & Witch craft & 5 & 33.3 & 10 & 66.7 & 15 & 6.9 & & \\
\hline & Dust & 1 & 50.0 & 1 & 50.0 & 48 & 21.9 & & \\
\hline & Others & 24 & 61.5 & 15 & 38.5 & 39 & 17.8 & & \\
\hline \multirow{6}{*}{ Occupation } & Student & 22 & 64.7 & 12 & 35.3 & 34 & 15.5 & \multirow{6}{*}{34.217} & \multirow{6}{*}{0.025} \\
\hline & Civil servant & 48 & 81.4 & 11 & 18.6 & 59 & 26.9 & & \\
\hline & Trader & 50 & 69.4 & 20 & 30.6 & 72 & 32.9 & & \\
\hline & House wife & 7 & 100 & 0 & 0 & 7 & 3.2 & & \\
\hline & Unemployed & 13 & 86.7 & 2 & 13.3 & 15 & 6.8 & & \\
\hline & Others & 26 & 81.3 & 6 & 18.7 & 32 & 14.7 & & \\
\hline \multirow{2}{*}{ Sex } & Male & 92 & 75.4 & 30 & 24.6 & 122 & 55.7 & 1310 & 0861 \\
\hline & Female & 76 & 78.4 & 21 & 21.6 & 97 & 44.3 & & \\
\hline & $0-15$ & 4 & 57.1 & 3 & 42.9 & 7 & 3.2 & & \\
\hline & $>15-30$ & 40 & 59.7 & 20 & 40.3 & 67 & 30.6 & & \\
\hline Age (Years) & $>30-45$ & 65 & 79.3 & 17 & 20.7 & 82 & 37.4 & 24.057 & 0.088 \\
\hline & $>45-60$ & 28 & 77.7 & 8 & 22.3 & 36 & 16.4 & & \\
\hline & $>60$ & 24 & 88.9 & 3 & 11.1 & 27 & 12.3 & & \\
\hline
\end{tabular}


Table 6. Binary logistic regression analysis for positive predictors of TB treatment delay.

\begin{tabular}{cccc}
\hline Variables & Odds Ratio & \multicolumn{2}{c}{ 95\% Confidence Interval } \\
\hline Patent medicine dealer & 12.3 & 3.22 & 36.23 \\
Private hospital & 10.3 & 5.73 & 17.94 \\
Prayer house & 7.2 & 2.75 & 23.64 \\
Traditional healer & 11.9 & 6.87 & 32.85 \\
Distance of DOTS facility & 3.6 & 1.41 & 16.35 \\
HIV status & 2.4 & 1.0 & 15.0 \\
Occupation & 5.3 & 1.1 & 14.3 \\
Symptoms experienced & 7.6 & 2.9 & 20.8 \\
\hline
\end{tabular}

Table 7. Period of TB patients presentation at the DOTS facility after onset of symptoms.

\begin{tabular}{cccc}
\hline Period (Weeks) & Frequency & Percent \\
\hline $1-4$ & 51 & 23.3 \\
$>4-6$ & 75 & 34.3 \\
$>6-8$ & 32 & 14.6 \\
$>8-12$ & 24 & 10.9 \\
$>12$ weeks & 37 & 16.9 \\
\hline
\end{tabular}

money was a major contributing factor to the patient delay [21] [22]. Factors that are significant predictors of patient delay in our study are HIV status, distance of DOTS facility, symptoms experienced, knowledge of the patients, and occupation of patients. All these factors are reported in the studies done in Ghana, Tanzania, and Gambia [4] [19] [23], while other factors reported to be significant in the studies such as educational level, sex, and age could not be found in our study. This could be due to the fact that our study was conducted in the state capital, and majority of the study participants are students (15.5\%), and civil servants (26.9\%).

Our findings in this study showed that there was relationship between patient's delay in seeking treatment and their knowledge of causes, transmission, and symptoms of TB experienced. This is similar to findings in the study done among rural Vietnamese adults, while the study done in Ibadan, Nigeria found no relationship [3] [24]. The low knowledge in our study might be due to low health education on TB through radio and television to the public by the National TB control programme.

The association of patient's delay with sex in the studies done in Ibadan, Nepal, and Bangladesh [3] [25] [26] were different from our findings in this study where there was no association, but the results were similar to studies done in Lagos, Ethiopia and India [12] [21] [27]. The proportion of females that delayed treatment were more than males in this study, which is comparable to the results reported in studies in Ghana, Nigeria, South Africa, and Tanzania [4] [28]-[30]. This difference could be attributed to socio-economic inequality between males and females in our study area. These findings indicate the need to increase tuberculosis awareness among females attending health facilities for other reasons such as ante-natal clinics, maternal and child health clinics for immunization and other services. The result in our study is different from what was observed in a study done in Southern India that employed men face difficulties to get a leave of absence from work to visit health services [31]. This delay was attributed to male behaviour which is socialization and care process that is detached from male practice [32]. All these reasons might be why more males delayed seeking treatment compared to females. However, more males (55.7\%) compare to females (44.3\%) were TB patients in our study. This is similar to reported cases in the studies conducted in Ibadan, Nigeria [3] [28].

In this study, patients with no formal and primary education delayed presentation at DOTS facilities compare to those who had secondary and tertiary education. This result is similar to findings reported in other studies conducted in Ethiopia and China where illiterate patients are 3.73 times more likely delay when compared with patients who had college and above education level [16] [33]-[35]. Also in Yemen, illiterate patients experienced much longer delay than literate patients. This could be due to the fact that those with secondary and tertiary education might have better information about TB, and may likely seek care early. 
The limitations of this study include recall bias, and perception of disease by the patients. However, only newly registered TB cases were included in our study, and the questionnaire were pretested.

\section{Conclusion}

Majority of TB patients in this study did not present early to health facilities. The positive predictors of delayed presentation for appropriate PTB treatment were first presentations at inappropriate treatment centers. There is need to intensify public health awareness among potential TB patients on the associated risks of treatment delay to prevent transmission. Collaboration between NTBLCP and unskilled health care providers should be intensified so that they could refer suspected PTB patients promptly to facilitate their treatment.

\section{Acknowledgements}

The authors would like to show appreciation to DOTS providers who participated in this study. We thank Oyiga Arinze, Thompson Nosgie, Ozogbo Stanley and Uche Chukwuemeka that collected the data for their commitment, and also study participants for their willingness to participate in the study.

\section{Conflict of Interests}

The authors declare that there is no conflict of interests regarding the publication of this paper.

\section{References}

[1] WHO (2013) Global Tuberculosis Control Report. WHO/HTM/TB/2013.16, Geneva. http://www.who.int/tb/publications/global_report/en

[2] Federal Ministry of Health, Nigeria (2015) National Tuberculosis and Leprosy Control Programme Workers Manual Revised 6th Edition, 1-5.

[3] Fatiregun, A.A. and Ejeckam, C.C. (2010) Determinants of Patient Delay in Seeking Treatment among Pulmonary Tuberculosis Cases in a Government Specialist Hospital in Ibadan, Nigeria. Tanzania Journal of Health Research, 12, 1-9. http://dx.doi.org/10.4314/thrb.v12i2.56398

[4] Lawn, S.D., Afful, B. and Acheampong, J.W. (1999) Pulmonary Tuberculosis in Adults: Factors Associated with Mortality at a Ghanaian Teaching Hospital. West African Journal of Medicine, 18, 270-274.

[5] World Health Organization (2006) The Stop TB Strategy, Building on and Enhancing DOTS to Meet the TB-related Millennium Development Goals. WHO, Geneva.

[6] Storla, D.G., Yimer, S. and Bjune, G.A. (2008) A Systematic Review of Delay in the Diagnosis and Treatment of Tuberculosis. BMC Public Health, 8, 15. http://dx.doi.org/10.1186/1471-2458-8-15

[7] World Health Organization (2006) Diagnostic and Treatment Delay in Tuberculosis an In-Depth Analysis of the Health-Seeking Behaviour of Patients and Health System Response in Seven Countries of the Eastern Mediterranean Region. WHO, Geneva.

[8] Paynter, S., Hayward, A., Wilkinson, P., Lozewicz, S. and Coker, R. (2004) Patient and Health Service Delays in Initiating Treatment for Patients with Pulmonary Tuberculosis: Retrospective Study. International Journal of Tuberculosis and Lung Disease, 8, 180-185.

[9] Aoki, M., Mori, T. and Shimao, T. (1985) Studies on Factors Influencing Patient's, Doctor's and Total Delay of Tuberculosis Case-Detection in Japan. Bulletin of the International Union against Tuberculosis, 60, 128-132.

[10] Ohmori, M., Ozasa, K., Mori, T., et al. (2005) Trends of Delays in Tuberculosis Case Finding in Japan and Associated Factors. International Journal of Tuberculosis and Lung Disease, 9, 999-1005.

[11] Demissie, M., Lindtjorn, B. and Berhance, Y. (2002) Patient and Health Service Delay in the Diagnosis of Pulmonary Tuberculosis in Ethiopia. BMC Public Health, 2, 23-31. http://dx.doi.org/10.1186/1471-2458-2-23

[12] Odusanya, O.O. and Babafemi, J.O. (2004) Patterns of Delays amongst Pulmonary Tuberculosis Patients in Lagos, Nigeria. BMC Public Health, 4, 46-51.

[13] Falodun, O.I., Cadmus, E.O., Alabi, P., et al. (2014) Delayed Treatment Seeking Behaviours and Associated Factors among Tuberculosis Patients in Ibadan, Nigeria. African Journal of Epidemiology, 2, 27-33.

[14] Mfinanga, S.G., Mutayoba, B.K., Kahwa, A., et al. (2008) The Magnitude and Factors Associated with Delays in Management of Smear Positive Tuberculosis in Dar es Salam, Tanzania. BMC Public Health, 8, 158.

[15] Raviglione, M. and Uplekar, M. (2006) WHO’s New Stop TB Strategy. The Lancet, 367, 952-955. 
http://dx.doi.org/10.1016/S0140-6736(06)68392-X

[16] Endalew, G., Muluken, A. and Gedefaw, A. (2014) Factors Associated with Patient's Delay in Tuberculosis Treatment in Bahir City Administration, Northwest Ethiopia. BioMed Research International, 2014, Article ID: 701429.

[17] Alexis, C., Andy, R., Mohammed, A.Y. and Luis, E.C. (2007) Duration and Associated Factors of Patient Delay during Tuberculosis Screening in Rural Cameroon. Tropical Medicine and International Health, 12, 1309-1314. http://dx.doi.org/10.1111/j.1365-3156.2007.01925.x

[18] Tegegn, A. and Yazachew, M. (2009) Delays in Tuberculosis Treatment and Associated Factors in Jimma Zone, Southwest Ethiopia. Ethiopian Health Science Journal, 19, 29-37.

[19] Wandwalo, E.R. and Morkve, O. (1998) Delay in Tuberculosis Case Finding and Treatment in Mwanza, Tanzania. International Journal of Tuberculosis and Lung Disease, 2, 635-640.

[20] Enwuru, C.A., Idigbe, E.O., Ezeobi, N.V. and Otegbeye, A.F. (2002) Care-Seeking Behavioural Patterns, Awareness and Diagnostic Processes in Patients with Smear and Culture-Positive Pulmonary Tuberculosis in Lagos, Nigeria. Transactions of the Royal Society of Tropical Medicine and Hygiene, 96, 614-616. http://dx.doi.org/10.1016/S0035-9203(02)90328-7

[21] Mesfin, M.M., Newell, J.N., Walley, J.D., Gessessew, A. and Madeley, R.J. (2009) Delayed Consultation among Pulmonary Tuberculosis Patients: A Cross Sectional Study of 10 DOTS Districts of Ethiopia. BMC Public Health, 9, 53. http://dx.doi.org/10.1186/1471-2458-9-53

[22] Needham, D.M., Godfrey, F.P. and Foster, S.D. (1998) Barriers to Tuberculosis Control in Urban Zambia: Economic Impact and Burden on Patients Prior to Diagnosis. International Journal of Tuberculosis and Lung Disease, 2, 811817.

[23] Lienhardt, C., Rowley, J., Manneh, K., et al. (2001) Factors Affecting Time Delay to Treatment in a Tuberculosis Control Programme in a Sub-Saharan African Country: The Experience of the Gambia. International Journal of Tuberculosis and Lung Disease, 5, 233-239.

[24] Hoa, N.P., Thorson, A.E.K., Long, N.H. and Diwan, V.K. (2003) Knowledge of Tuberculosis Associated HealthSeeking Behaviour among Rural Vietnamese Adults with a Cough for at Least Three Weeks. Scandinavian Journal of Public Health, 31, 59-65. http://dx.doi.org/10.1080/14034950310015121

[25] Yamasaki, N.M., Ozasa, K., Yamada, N., et al. (2001) Gender Difference in Delays to Diagnosis and Health Care Seeking Behaviour in a Rural Area of Nepal. International Journal of Tuberculosis and Lung Disease, 5, 24-31.

[26] Giasuddin, A. and Jalaluddin, A. (2004) Gender Difference in Treatment Seeking Behaviours of Tuberculosis Cases in Rural Communities of Bangladesh. National TB Control Programme, Ministry of Health and FW, Dhaka.

[27] Rajeswari, R., Chandrasekaran, V., Suhadev, M., et al. (2002) Factors Associated with Patient and Health System Delays in the Diagnosis of Tuberculosis in South India. International Journal of Tuberculosis and Lung Disease, 6, 789795.

[28] Falodun, O.I., Cadmus, E.O., Alabi, P., et al. (2014) Delayed Treatment Seeking Behaviours and Associated Factors among Tuberculosis Patients in Ibadan, Nigeria. African Journal of Epidemiology, 2, 27-33.

[29] Pronyk, R.M., Makhubele, M.B., Hargreaves, J.R., Tollman, S.M. and Hausler, H.P. (2001) Assessing Health Seeking Behaviour among Tuberculosis Patients in Rural South Africa. International Journal of Tuberculosis and Lung Disease, 5, 619-627.

[30] Sayoki, G.M., Beatrice, K.M., Amos, K., et al. (2008) The Magnitude and Factors Associated with Delays in Management of Smear Positive Tuberculosis in Dar es Salam, Tanzania. BMC Health Services Research, 8, 8-15.

[31] Balasubramanian, R., Garg, R., Santha, T., et al. (2004) Gender Disparities in Tuberculosis: Report from a Rural DOTS Programme in South India. International Journal of Tuberculosis and Lung Disease, 8, 323-332.

[32] Courtenay, W.H. (2000) Constructions of Masculinity and Their Influence on Men's Well-Being: A Theory of Gender and Health. Social Science \& Medicine, 50, 1385-1401. http://dx.doi.org/10.1016/S0277-9536(99)00390-1

[33] Zhou, C., Tobe, R.G., Chu, J., et al. (2012) Detection Delay of Pulmonary Tuberculosis Patients among Migrants in China: A Cross-Sectional Study. International Journal of Tuberculosis and Lung Disease, 16, 1630-1636. http://dx.doi.org/10.5588/ijtld.12.0227

[34] Hussen, A., Biadgilign, S., Tessema, F., et al. (2012) Treatment Delay among Pulmonary Tuberculosis Patients in Pastoralist Communities in Bale Zone, South-East Ethiopia. BMC research Notes, 5, 7-11.

[35] Date, J. and Okita, K. (2005) Gender and Literacy: Factors Related to Diagnostic Delay and Unsuccessful Treatment of Tuberculosis in the Mountainous Area of Yemen. International Journal of Tuberculosis and Lung Diseases, 9, 680685. 


\section{Abbreviations}

UNTH: University of Nigeria Teaching Hospital DOTS: Direct Observe Treatment Short Course

OR: Odds Ratio

CI: Confidence Interval

SPSS: Statistical Packages for Social Science

TB: Tuberculosis

MTB/RIF: Mycobacterium Tuberculosis/Rifampicin Resistant

HIV: Human Immunodeficiency Virus

NTBLCP: National Tuberculosis and Leprosy Control Programme 